\title{
Impact of Hydrolyzed Whey Protein on the Molecular Interactions and Cross-Linking Density in Whey Protein Isolate-Based Films
}

\author{
Markus Schmid, ${ }^{1,2}$ Sandra Pröls, ${ }^{1,3}$ Daniel M. Kainz, ${ }^{1}$ \\ Felicia Hammann, ${ }^{1}$ and Andreas Stäbler ${ }^{1}$ \\ ${ }^{1}$ Fraunhofer Institute for Process Engineering and Packaging IVV, Giggenhauser Strasse 35, 85354 Freising, Germany \\ ${ }^{2}$ Chair for Food Packaging Technology, Technische Universität München, Weihenstephaner Steig 22, 85354 Freising, Germany \\ ${ }^{3}$ Department of Food Technology, Fulda University of Applied Sciences, Marquardstraße 35, 36039 Fulda, Germany \\ Correspondence should be addressed to Markus Schmid; markus.schmid@ivv.fraunhofer.de
}

Received 12 May 2016; Accepted 12 October 2016

Academic Editor: Qinglin Wu

Copyright (C) 2016 Markus Schmid et al. This is an open access article distributed under the Creative Commons Attribution License, which permits unrestricted use, distribution, and reproduction in any medium, provided the original work is properly cited.

\begin{abstract}
The effect of the amount of hydrolyzed WPI (h-WPI) in WPI-based films on the technofunctional properties and structure of the films has not hitherto been systematically researched. The main objective of this study was therefore to explore the quantitative and qualitative molecular interactions and structures of these films. Different buffer systems were used for the solubility studies to obtain information about the qualitative molecular interactions. Swelling studies were performed to provide qualitative statements about the WPI network. In addition, the cross-linking density (CLD) of the WPI-based films was derived from the swelling tests. The measurements showed that increasing the h-WPI content decreases the CLD significantly. The CLD values of films with $0 \%$ and $50 \% \mathrm{~h}$-WPI content were $1.61 \cdot 10^{-4} \mathrm{~mol} \cdot \mathrm{cm}^{-3}$ and $0.25 \cdot 10^{-4} \mathrm{~mol} \cdot \mathrm{cm}^{-3}$. The study indicates that noncovalent interactions have more influence on barrier properties than the cross-linking density through disulphide bonds. In general, the results of the swelling tests correlated with the solubility studies.
\end{abstract}

\section{Introduction}

The primary function of food packaging is to protect food against external influences such as oxygen or water vapor [1]. Food packaging materials must therefore provide an adequate barrier against these gases, especially for the application with sensitive food products. This is usually ensured by incorporating barrier materials in multilayer structures of food packages. Suchlike barrier materials are commonly derived from petrochemical resources. However, the demand for degradable packaging material is growing.

Consequently, a significant number of works have been published on biodegradable packaging materials from renewable resources such as wheat gluten, soy protein, casein, and whey proteins [2]. Whey protein isolate- (WPI-) based films show excellent barrier properties classifying them as a suitable new biomaterial for packaging applications $[3,4]$.
Whey protein isolate is a mixture of different whey proteins. These proteins can be linked together through thermal, enzymatic, and chemical treatments [5]. During the treatment the proteins form intermolecular bonds resulting in a polymeric network. The strongest of these cross-links are covalent disulphide bridges. The barrier properties of WPIbased films can be improved by increasing the number of strong intermolecular interactions such as covalent crosslinks $[6,7]$. Nevertheless, more noncovalent interactions also improve the barrier properties. In this study the influences of both disulphide and noncovalent interactions are analyzed quantitatively and qualitatively in terms of barrier properties against oxygen and water vapor. The results should enable material developer to achieve the best barrier properties for packaging solutions with an economic production method.

A qualitative determination of the WPI intermolecular interactions can be achieved by conducting solubility tests 
using different buffer systems. These buffers contain chemical constituents such as thiourea, urea, or dithiothreitol capable of specifically influencing certain intermolecular bonds. Conclusions about the types of interactions between polypeptide chains can be drawn by comparing protein solubility in the different buffer systems [8]. However, to the author's knowledge, no other studies investigate the crosslinking density (CLD) of whey protein-based films. The CLD is the absolute value of cross-links in $\mathrm{mol} \cdot \mathrm{cm}^{-3}$ or $\mathrm{mol} \cdot \mathrm{g}^{-1}$. In this study formulations with different ratios of native and hydrolyzed whey protein were investigated. By this, the average molecular weight in the protein film was varied, resulting in different molecular weights between two cross-links $\left(M_{c}\right)$. To determine the CLD as well as the $M_{c}$ value, swelling studies have been carried out. However, the determination of the CLD value required additional tests, as the unknown parameter $\chi$ had to be calculated. $\chi$ is an interaction parameter between distilled water and WPIbased films. According to Peters et al. [9] and Karimi et al. [10], $\chi$ can be determined using water vapor sorption isotherm measurements. In addition to these aims, the barrier properties of the different WPI-based films were analyzed and correlated with the calculated CLD values.

\section{Materials and Methods}

2.1. Solution Preparation and Coating. WPI and h-WPI were mixed with a magnetic stirrer (IKA, RH basic, Staufen, Germany) to give the following WPI: h-WPI ratios: $10: 0,9: 1$, $8: 2,7: 3,6: 4$, and $5: 5$. The different ratios of $h-W P I$ and WPI ( $10 \%$ w/w, BiPro, Davisco Foods International Inc., Le Sueur, Minnesota, USA) were then dissolved in deionized water using an electric stirrer (Thermomix 31-1, Vorwerk Deutschland Stiftung \& Co. KG, Wuppertal, Germany) according to Mchugh et al. [12]. One liter of the solution was heated and kept at $90^{\circ} \mathrm{C}$ for 30 minutes under constant stirring. After cooling down, glycerol (Merck, Darmstadt, Germany) was added to achieve a plasticizer amount of $6.67 \%$ (wt\%) in the solution. Afterwards the mixture was stirred for another $30 \mathrm{~min}$. Finally, the solution was transferred to a laboratory bottle. The sample was degassed in an ultrasonic bath for 15 minutes (DT 514H, Bandelin electronic GmbH \& Co. KG, Berlin, Germany).

Cast films were used for the swelling studies and to determine the technofunctional properties. For film casting $18 \mathrm{~g} \pm 0.5 \mathrm{~g}$ of the WPI formulation was added to a polystyrene Petri dish (Greiner Bio One International, $120 \mathrm{~mm} \times 120 \mathrm{~mm}$ $\times 14.5 \mathrm{~mm}$ ). By using this amount dried films with a constant thickness of $200 \pm 20 \mu \mathrm{m}$ were obtained. Figure-of-eight movements were performed with the Petri dish to achieve a homogenous distribution. Then the Petri dishes were placed on an even surface. The storage time was 14 days at $23^{\circ} \mathrm{C}$ and $50 \%$ r.h. The resulting films were easily peeled off the Petri dishes with the help of a cutter knife and tweezer after the drying phase.

2.2. Protein Solubility Study. Protein solubility studies provide information about the qualitative molecular interaction in a protein network [8]. Six different buffer systems were
TABLE 1: Combinations of selective reagents and the cleaving effect of these combinations.

\begin{tabular}{|c|c|c|c|c|c|c|}
\hline Number & $\begin{array}{c}\text { Extracting } \\
\text { buffer system }\end{array}$ & $\mathrm{PP}$ & $\mathrm{U}$ & $\mathrm{TH}$ & DTT & $\begin{array}{c}\text { Cleaved } \\
\text { interactions by } \\
\text { respective buffer } \\
\text { system }\end{array}$ \\
\hline 1 & $\mathrm{PP}$ & + & - & - & - & No interactions \\
\hline 2 & $\mathrm{PP}+\mathrm{TH}$ & + & - & + & - & $\begin{array}{l}\text { Hydrophobic } \\
\text { interactions }\end{array}$ \\
\hline 3 & $\mathrm{PP}+\mathrm{TH}+\mathrm{D}$ & + & - & + & + & $\begin{array}{l}\text { Hydrophobic } \\
\text { interactions } \\
\text { Disulfide bonds }\end{array}$ \\
\hline 4 & $\mathrm{PP}+\mathrm{U}+\mathrm{TH}$ & + & + & + & - & $\begin{array}{l}\text { Hydrophobic } \\
\text { interactions } \\
\text { Hydrogen bonds }\end{array}$ \\
\hline 5 & $\mathrm{PP}+\mathrm{U}+\mathrm{D}$ & + & + & - & + & $\begin{array}{l}\text { Hydrogen and } \\
\text { disulfide bonds }\end{array}$ \\
\hline
\end{tabular}

used. These were combinations of the selected regents: $0.1 \mathrm{M}$ phosphate buffer (PP), $1 \mathrm{M}$ thiourea (TH), $50 \mathrm{mM}$ dithiothreitol (D), and $8 \mathrm{M}$ urea (U). These different buffer systems are capable of breaking specific molecular interactions in the protein network. In Table 1, the different buffer systems as well as the interactions influenced are listed $[13,14]$.

The stored WPI-based coatings $\left(50 \%\right.$ r.h. and $\left.23^{\circ} \mathrm{C}\right)$ were peeled off the PTFE layer and the nitrogen content of the samples was determined using the method according to Dumas for calculation of the protein content in dry matter. The total amount of nitrogen in mass percent was multiplied by a factor of 6.25 to get the raw protein content of the film. This value had to be referred to the dry matter, which was determined using a general method of the Fraunhofer IVV in a thermographic analyzer LECO TGA 601 (see method description [14]).

For solubility tests the peeled off protein film was frozen with liquid nitrogen (Linde AG, München, Germany) and powdered using a laboratory mill (ZM 100, F. Kurt Retsch GmbH \& Co. KG, Haan, Germany). The milling step was applied to increase the sample surface, thus enabling solvent access to the protein chains during extraction.

$0.5 \mathrm{~g}$ of the powdered protein and $10 \mathrm{~mL}$ of the respective buffer were added to $100 \mathrm{~mL}$ Duran laboratory glass bottles. For the extraction step these bottles were placed in a water bath $\left(25^{\circ} \mathrm{C}\right)$ and stirred using a magnetic stirrer (IKA, RH basic, Staufen, Germany). After 2.5 hours, the suspensions were centrifuged for 15 minutes at $20^{\circ} \mathrm{C}$ and $16000 \times \mathrm{g}$ using a lab centrifuge (Sigma Laborzentrifugen $\mathrm{GmbH}$, Osterode am Harz, Germany). The rapid and sensitive Bradford protein assay was applied to determine the protein concentration in the supernatant. It was based on the color change of the reagent Coomassie Brilliant Blue G-250 (CBBG) from red (absorptions maximum: $470 \mathrm{~nm}$ ) to blue (absorptions maximum: $595 \mathrm{~nm}$ ) in the presence of proteins. The photometric measurement was performed at a wavelength of $595 \mathrm{~nm}[15$, 16].

For calibration measurements with BSA standard proteins were performed using solutions with the concentrations 
$5,10,15$, and $20 \mu \mathrm{g} \cdot \mathrm{mL}^{-1}[14]$. After preparation of the calibration curve, the protein extracts were diluted with distilled water to enable measurements within the calibration range. A predilution step was needed for high protein concentrations. All samples were mixed thoroughly using a Vibrofix VF1 electronic stirrer to achieve a homogenous distribution. $800 \mu \mathrm{L}$ of the diluted protein extracts was mixed with $200 \mu \mathrm{L}$ color reagent $\mathrm{CBBG}$ in a $1.5 \mathrm{~mL}$ cuvette. A completely homogenous mixture was achieved by using single cuvette stirrers. Generally the samples were incubated at room temperature for 20 minutes. After the incubation time, the photometric measurement was carried out using the WinASPECT PLUS program (Analytik Jena, Jena, Germany) at a wavelength of $595 \mathrm{~nm}$. A measurement of air served as reference. All values were determined six times for statistical analysis.

The calculation of the protein solubility was performed using the following equation. The ratio of the supernatant protein content to the protein content of the films was crucial [17]:

$$
\text { soluble proteins }=\frac{\text { proteins } \cdot V \cdot(1 / \mathrm{DF})}{M \cdot \text { protein in dry matter }},
$$

where soluble proteins [\%] is the amount of protein solubilized by the respective buffer and proteins $\left[\mu \mathrm{g} \cdot \mathrm{mL}^{-1}\right]$ is the protein concentration determined with the Bradford assay. $V$ is the volume of the buffer solution used for extraction [ $\mathrm{mL}]$, $M$ is the mass of the specimen $[g]$, DF is the dilution factor used in the Bradford assay, and protein in dry matter is the dry matter content of the specimen [\%].

\subsection{Swelling Studies to Determine the Degree of Cross-Linking.} According to DIN EN ISO 175:2000 the degree of swelling (DoS) was determined in order to calculate the CLD. The cast films were cut to a size of $60 \mathrm{~mm} \times 60 \mathrm{~mm}$ using a stamp $(60 \mathrm{~mm} \times 60 \mathrm{~mm})$ and a cutter. The dry films were weighed before the swelling test $\left(m_{1}\right)$ and placed in a preweighted sample container (wide-necked glass, Nalgene, Carl Roth $\mathrm{GmbH}$ Co. KG, volume: $500 \mathrm{~mL}$ ). $288 \mathrm{~mL}$ distilled water having a temperature of $23^{\circ} \mathrm{C}$ was added to the dry films in the sample container $(8 \mathrm{~mL}$ of swelling medium per square centimeter of the surface area of the specimens is recommended according to DIN EN ISO 175:2000). The containers were closed with lids and stored at $23^{\circ} \mathrm{C}$ and $50 \%$ r.h. for 24 hours. After the swelling time of 24 hours, the swollen samples were removed from the containers and adherent liquids were rapidly removed using a tissue paper (Katrin Plus Facial Tissue, Metsä Tissue Limited, Walton on Thames, Surrey, $\mathrm{UK})$. The sample mass $\left(m_{2}\right)$ was measured immediately using a precision balance (Sartorius 1702, Sartorius AG, Göttingen, Germany). Then the films were dried at $65^{\circ} \mathrm{C}$ under high air circulation in a drying cabinet until weight constancy was achieved. The dry films were weighed again using a precision balance $\left(m_{3}\right)$. Since $m_{3}$ is the actual weight of the polymer film in the swelling test, it is used to calculate the DoS and the cross-linking density.

The DoS can be calculated as follows:

$$
\operatorname{DoS}[\%]=\frac{m_{2}-m_{3}}{m_{3}} \cdot 100,
$$

where DoS is the degree of swelling [\%], $m_{2}$ is weight of the swollen films after swelling [g], and $m_{3}$ is weight of the pure films (without swelling medium) [g].

To ensure optimum statistical evaluation, 5-fold determination was performed.

2.4. Determination of the Cross-Linking Density from the Water Vapor Sorption Isotherm. Water vapor sorption isotherms (WVSI) were measured with the SPS sorption test system SPS- $1 \mu$ High Load (ProUmid GmbH, Ulm, Germany) at a constant temperature of $23^{\circ} \mathrm{C}$. The WPI-based cast films were cut into circles with a diameter of $50 \mathrm{~mm}$. The cut samples were placed in small bowls of known-mass and were weighed during the measurement using a builtin precision balance. The measurement was started with a relative humidity of $50 \%$. When the sample mass did not change by more than $0.002 \mathrm{mg} \cdot \mathrm{min}^{-1}$ for $300 \mathrm{~min}$ or the material was subjected to the adjusted r.h. for a maximum of $1500 \mathrm{~min}$, the sample weight was logged. For the next measurement the r.h. was increased by $10 \%$ and the weight measuring started again. The r.h. was increased in steps of $10 \%$ to $90 \%$ r.h., then decreased in steps of $10 \%$ to $0 \%$ r.h., and finally increased again to the starting value of $50 \%$ r.h. In every step the sample weight was measured once the mentioned conditions were fulfilled.

The cross-link density $\left[\mathrm{mol} \mathrm{g}^{-1}\right]$ is generally defined as $[18,19]$

$$
\mathrm{CLD}=\frac{1}{M_{c}}
$$

where $M_{c}$ is number average molecular weight of the polymer between cross-links $\left[\mathrm{g} \cdot \mathrm{mol}^{-1}\right]$.

In this paper the degree of cross-link is also defined with the mole fraction of cross-linked units [20]:

$$
\mathrm{DoC}=\frac{\overline{M_{0}}}{M_{c}},
$$

where $\overline{M_{0}}$ is molecular weight of the mean amino acid of WPI $\left[\mathrm{g} \cdot \mathrm{mol}^{-1}\right.$ ] and $M_{c}$ is number average molecular weight of the polymer between cross-links $\left[\mathrm{g} \cdot \mathrm{mol}^{-1}\right]$. This definition indicates directly the ratio of amino acids which are involved in cross-links and is therefore an illustrative value. The used $\overline{M_{0}}$ was $123.3 \mathrm{~g} \cdot \mathrm{mol}^{-1}$ (see Supplementary Information available online at http://dx.doi.org/10.1155/2016/3723758).

$M_{c}$ can be determined by swelling experiments using the Flory-Rehner equation [21-23]:

$$
M_{c}=-\frac{\rho_{\mathrm{WPI}} \cdot V_{2} \cdot\left(\varphi_{1}^{1 / 3}-\varphi_{1} / 2\right)}{\left(\ln \left(1-\varphi_{1}\right)+\varphi_{1}+\chi \cdot \varphi_{1}^{2}\right)},
$$

where $M_{c}$ is number average molecular weight of the polymer between cross-links $\left[\mathrm{g} \cdot \mathrm{mol}^{-1}\right], V_{2}$ is molar volume of deionized water $\left[\mathrm{cm}^{3} \cdot \mathrm{mol}^{-1}\right], \rho_{\text {WPI }}$ is WPI film density $1.40 \pm$ $0.06 \mathrm{~g} \cdot \mathrm{cm}^{-3}, \varphi_{1}$ is volume fraction of polymer in swollen gel [-], and $\chi$ is interaction parameter of WPI film and water $[-]$. 
It was assumed that a binary mixture of WPI film (1) and water (2) exists. The plasticizer glycerol is neglected because water as swelling medium dissolves it out of the WPI film during the swelling test. The volume fraction of polymer in swollen gel $\varphi_{1}$ is defined as

$$
\varphi_{1}=\frac{m_{\mathrm{WPI}} / \rho_{\mathrm{WPI}}}{m_{\mathrm{WPI}} / \rho_{\mathrm{WPI}}+m_{s} / \rho_{s}},
$$

where $m_{\text {WPI }}$ is mass of the polymer in the swollen gel [g], $\rho_{\text {WPI }}$ is WPI film density $\left[\mathrm{g} \cdot \mathrm{cm}^{-3}\right], m_{s}$ is mass of the solvent water in the swollen gel $[\mathrm{g}]$, and $\rho_{s}$ is density of water $\left[\mathrm{g} \cdot \mathrm{cm}^{-3}\right]$.

The interaction parameter $\chi$ was determined by fitting the Flory-Huggins equation with the method of least squares to the measured WVSI using Excel Solver tool. The FloryHuggins equation is defined in its simplified form as $[24,25]$

$$
\frac{\Delta \mu^{\operatorname{mix}}}{R T}=\ln a_{w}=\ln \left(1-\varphi_{1}\right)+\varphi_{1}+\chi \cdot \varphi_{1}^{2}
$$

where $\Delta \mu^{\text {mix }}$ is difference of the chemical potential of the mixture of WPI film and water $\left[\mathrm{J} \cdot \mathrm{mol}^{-1}\right], R$ is ideal gas constant $\left[\mathrm{J} \cdot \mathrm{mol}^{-1} \cdot \mathrm{K}^{-1}\right], T$ is temperature $[\mathrm{K}], \varphi_{1}$ is volume fraction of polymer in swollen gel $[-]$, and $\chi$ is interaction parameter [-].

Equation (7) was used in the form

$$
a_{w}=\exp \left(\ln \left(1-\varphi_{1}\right)+\varphi_{1}+\chi \cdot \varphi_{1}^{2}\right)
$$

for the fitting process due to an imbalanced influence of the logarithmic water activity on the sum of squared errors (SSE) at low water activities.

2.5. Statistical Methods. The multiple $t$-test was performed to determine whether there was any significant difference between the experimental treatments with $p<0.05$ for at least five replicates.

The Gaussian error propagation was used to estimate the propagation of uncertainty of $M_{c}$. The $95 \%$ Confidence intervals of the mean were always rounded up. If the first significant digit of the confidence interval was three or higher, the confidence interval was rounded off to one significant digit. If the first significant digit was one or two, the confidence interval was rounded off to two significant digits.

The software Visual-XSel 12.0 (CRGRAPH, Munich, Germany) was used. In addition, all the measured data were tested for a normal distribution, with Grubb's test being used to detect and eliminate outliers in a data set.

The residual standard error (RSE) for the fitting curve is defined as

$$
\mathrm{RSE}_{n-p}=\sqrt{\frac{\sum_{i=1}^{n}\left(Y_{i}-\widehat{Y}_{i}\right)^{2}}{n-p}}
$$

where $n$ is number of observations, $Y_{i}$ is value of the $i$.observation, $\widehat{Y}_{i}$ is predicted/modelled value, and $p$ is number of regression coefficients.

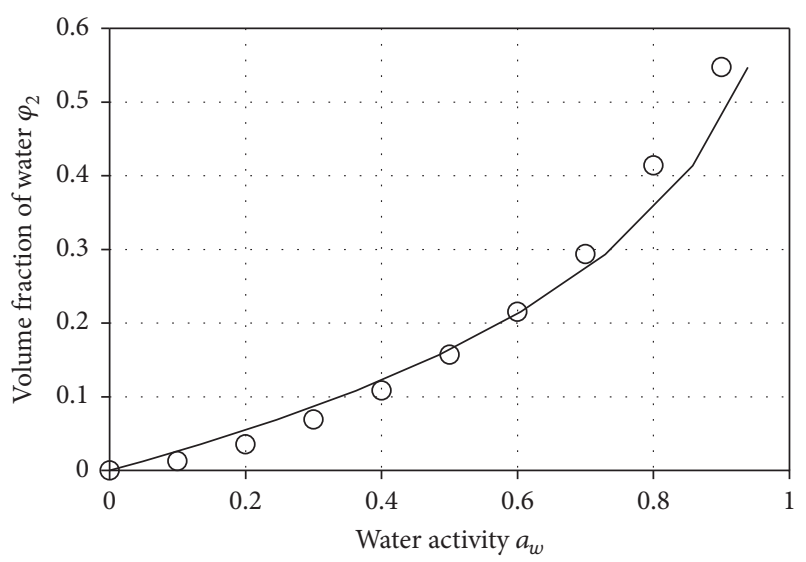

O WVSI (experiment BioZate5_5)

FIGURE 1: Water vapor sorption isotherm (WVSI) of the sample BioZate5_5 and the calculated sorption isotherm by the FloryHuggins (FH) equation.

\section{Results and Discussion}

3.1. Cross-Linking Density and Degree of Cross-Linking. The sorption of water vapor in materials is characterized by the water vapor sorption isotherm (WVSI) [26]. Table 2 shows the WVSI results for WPI-based films with different h-WPI and WPI contents, the calculated $\chi$ values, and the residual standard error (RSE).

The WVSI curve of BioZate5_5 and the fitted FloryHuggins model curve (RSE of 0.044) are illustrated in Figure 1.

Since there is no significant difference between the determined interaction parameters, the mean interaction parameter $\bar{\chi}$ and its 95\% confidence interval were calculated to be $0.460 \pm 0.017$. It was assumed that $\chi$ could decrease with increasing h-WPI content (indicating better interaction of water with WPI) due to higher solubility of the films with increasing h-WPI content (see solubility study). This effect could not be observed and indicates that the interaction parameter of pure water and WPI is presumably the same as with h-WPI.

As described in literature $[22,27]$ it was not possible to calculate $M_{c}$ using the sorption isotherms because the elastic term in the Flory-Rehner equation had no significant influence on the result. Therefore swelling tests were preformed. The results can be seen in Table 3 .

The $95 \%$ confidence intervals are corresponding to a relative error between 20 and $40 \%$ of $M_{c}$. The relative error of the sample BioZate5_5 was even 67\% and should therefore only be seen as a tendency at very high h-WPI contents in WPIbased films. The reasons for the low precision are the very high swelling degrees of the films. Even films with no h-WPI content had a DoS of around $400 \%$. The DoS increases with increasing h-WPI ratio. For example, the volume fraction of polymer in the swollen gel of sample BioZate5_5 was only 5\% resulting in a DoS of $1100 \%$. These very high DoS made the handling of the swollen films extremely difficult resulting in high measuring errors for films with high h-WPI contents. 
TABLE 2: Volume fraction of water $\left(\varphi_{2}=1-\varphi_{1}\right)$ in the WPI-based films at different water activities and the resulting $\chi$.

\begin{tabular}{|c|c|c|c|c|c|c|}
\hline$a_{w}$ & $\begin{array}{c}\varphi_{2} \text { of } \\
\text { BioZate }\end{array}$ & $\begin{array}{c}\varphi_{2} \text { of } \\
\text { BioZate }\end{array}$ & $\begin{array}{c}\varphi_{2} \text { of } \\
\text { BioZate }\end{array}$ & $\begin{array}{c}\varphi_{2} \text { of } \\
\text { BioZate }\end{array}$ & $\begin{array}{c}\varphi_{2} \text { of } \\
\text { BioZate }\end{array}$ & $\begin{array}{c}\varphi_{2} \text { of } \\
\text { BioZate }\end{array}$ \\
\hline & 10_0 & 9_1 & 8_2 & 7_3 & $6 \_4$ & 5_5 \\
\hline 0.0 & 0.000 & 0.000 & 0.000 & 0.000 & 0.000 & 0.000 \\
\hline 0.1 & 0.017 & 0.020 & 0.015 & 0.014 & 0.016 & 0.012 \\
\hline 0.2 & 0.042 & 0.046 & 0.040 & 0.038 & 0.041 & 0.035 \\
\hline 0.3 & 0.073 & 0.078 & 0.073 & 0.070 & 0.074 & 0.069 \\
\hline 0.4 & 0.109 & 0.114 & 0.109 & 0.108 & 0.112 & 0.108 \\
\hline 0.5 & 0.153 & 0.160 & 0.155 & 0.155 & 0.160 & 0.157 \\
\hline 0.6 & 0.208 & 0.216 & 0.213 & 0.213 & 0.218 & 0.215 \\
\hline 0.7 & 0.281 & 0.292 & 0.289 & 0.290 & 0.296 & 0.293 \\
\hline 0.8 & 0.394 & 0.403 & 0.400 & 0.408 & 0.416 & 0.414 \\
\hline 0.9 & 0.521 & 0.533 & 0.527 & 0.535 & 0.538 & 0.547 \\
\hline Determined $\chi$ & 0.482 & 0.442 & 0.468 & 0.468 & 0.441 & 0.460 \\
\hline $\mathrm{RSE}_{9}$ & 0.031 & 0.027 & 0.035 & 0.039 & 0.036 & 0.044 \\
\hline
\end{tabular}

TABLE 3: Volume fraction of polymer in swollen gel $\varphi_{1}$, number average molecular weight of the polymer between cross-links $M_{c}$, cross-link density, and degree of cross-linking with 95\% confidence intervals of different h-WPI ratios in WPI-based films.

\begin{tabular}{|c|c|c|c|c|c|}
\hline $\begin{array}{l}\text { Sample name } \\
\text { WPI : h-WPI }\end{array}$ & $\begin{array}{l}\text { DoS } \\
{[\%]}\end{array}$ & $\begin{array}{c}\varphi_{1} \\
{[-]}\end{array}$ & $\begin{array}{c}M_{c} \\
{\left[\mathrm{~g} \cdot \mathrm{mol}^{-1}\right]}\end{array}$ & $\begin{array}{c}\text { CLD } \\
\cdot 10^{-4}\left[\mathrm{~mol} \cdot \mathrm{g}^{-1}\right]\end{array}$ & $\begin{array}{c}\text { DoC } \\
{[\%]}\end{array}$ \\
\hline $\begin{array}{l}\text { BioZate10_0 } \\
10: 0\end{array}$ & $400 \pm 9$ & $0.1222 \pm 0.0023$ & $8700 \pm 1800$ & $1.15 \pm 0.24$ & $1.42 \pm 0.30$ \\
\hline $\begin{array}{l}\text { BioZate9_1 } \\
9: 1\end{array}$ & $380 \pm 60$ & $0.126 \pm 0.015$ & $8100 \pm 2800$ & $1.2 \pm 0.5$ & $1.5 \pm 0.6$ \\
\hline $\begin{array}{l}\text { BioZate8_2 } \\
8: 2\end{array}$ & $590 \pm 40$ & $0.088 \pm 0.005$ & $18000 \pm 5000$ & $0.55 \pm 0.15$ & $0.67 \pm 0.19$ \\
\hline $\begin{array}{l}\text { BioZate7_3 } \\
7: 3\end{array}$ & $810 \pm 100$ & $0.066 \pm 0.009$ & $34000 \pm 13000$ & $0.29 \pm 0.11$ & $0.36 \pm 0.14$ \\
\hline $\begin{array}{l}\text { BioZate6_4 } \\
6: 4\end{array}$ & $860 \pm 80$ & $0.063 \pm 0.006$ & $38000 \pm 13000$ & $0.27 \pm 0.09$ & $0.33 \pm 0.11$ \\
\hline $\begin{array}{l}\text { BioZate5_5 } \\
5: 5\end{array}$ & $1100 \pm 400$ & $0.052 \pm 0.017$ & $60000 \pm 40000$ & $0.18 \pm 0.13$ & $0.22 \pm 0.16$ \\
\hline
\end{tabular}

At low h-WPI contents the measuring error of $\chi$ contributes most to the error of $M_{c}$.

Nevertheless the accuracy of the test seems to be high. Assuming that all cysteine-residues are involved in crosslinking, an $M_{c}$ of $5947 \mathrm{~g} \cdot \mathrm{mol}^{-1}$ is calculated theoretically for the sample BioZate10_0 (see Supplementary Information). In the swelling test an $M_{c}$ of $8700 \mathrm{~g} \cdot \mathrm{mol}^{-1}$ was determined. Since it is unlikely that all thiol-groups are forming cross-links, this result seems to be reasonable. In addition the theoretic value is within the confidence interval. $M_{c}$ increases with a higher proportion of hydrolyzed WPI resulting in a decrease of the CLD and DoC except for sample BioZate9_1.

Generally with an increasing h-WPI ratio more peptides are solubilized during the swelling test. Assuming that all of plasticizer was dissolved the sample BioZate10_0 had a protein mass loss of around $7 \%$ during the swelling test while the sample BioZate5_5 lost $21 \%$ of its original mass. But no significant difference in $M_{c}$ was measured between $0 \%$ and $10 \%$ hWPI content in the sample. Also no significant increase in the protein mass loss during the swelling test of BioZate10_0 and BioZate9_1 was measured. This could indicate that at h-WPI contents below $10 \%$ most of the h-WPI peptides can bond to the WPI proteins.

According to the calculated DoC for samples BioZate10_0 and BioZate9_1 around $1.4-1.5 \%$ of all proteins are involved in cross-linking resulting in a CLD of around $1.2 \cdot 10^{-4} \mathrm{~mol} \cdot \mathrm{g}^{-1}$. In literature the CLD is sometimes multiplied by the density. In this case the CLD would be $1.7 \cdot 10^{-4} \mathrm{~mol} \cdot \mathrm{cm}^{-3}$ as shown in Figure 2. Ahmed et al. [18] measured CLD values for filled and unfilled natural rubber between 2.0 and $2.6 \cdot 10^{-4} \mathrm{~mol} \cdot \mathrm{cm}^{-3}$. By comparing the results it can be deduced that WPIbased films have a slightly lower CLD than natural rubber. Nevertheless WPI-based films show thermoset properties as earlier mechanical studies showed [11, 28]. This indicates that noncovalent interactions have a greater influence on the WPI-based film properties than expected. These noncovalent 


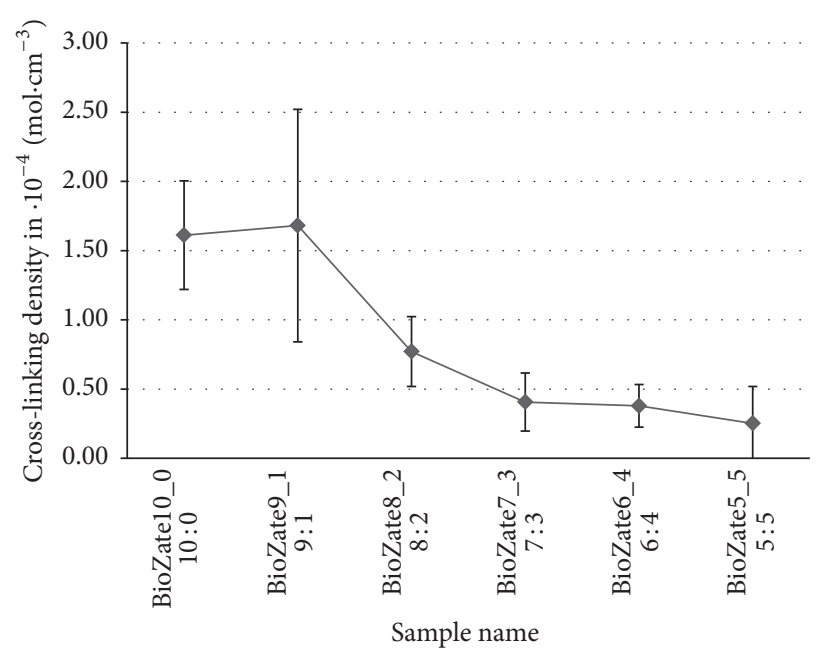

Film component ratio [WPI : h-WPI]

FIGURE 2: Cross-linking density of all samples in $\mathrm{mol} \cdot \mathrm{cm}^{-3}$ with $95 \%$ confidence intervals.
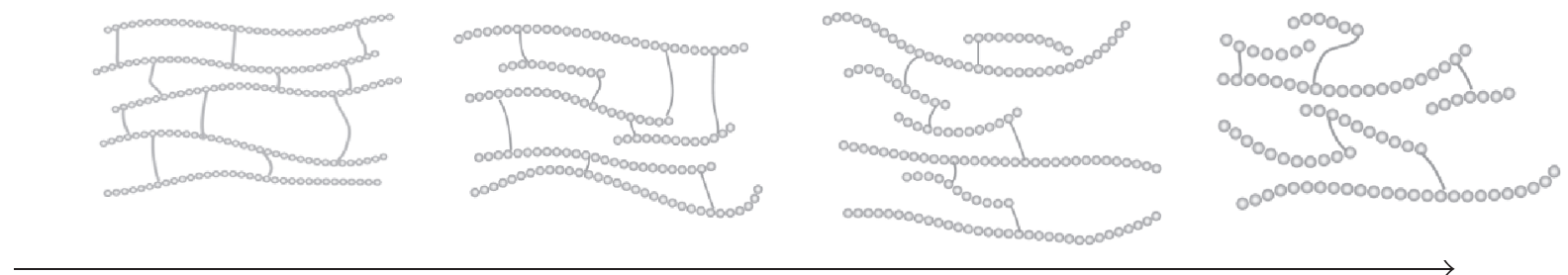

Increasing ratio of hydrolyzed whey protein isolate

FIgURE 3: Protein network structure in WPI-based films with increasing ratio of h-WPI (on the left: BioZate10_0; on the right: BioZate5_5).

interactions must mostly be negated by water resulting in high degrees of swelling of $>400 \%$ which are comparable with natural rubber polymers (compare [18]).

Increasing the h-WPI ratio to $20 \%$ halved the CLD to $0.55 \cdot 10^{-4} \mathrm{~mol} \cdot \mathrm{g}^{-1}$ compared to a film without hWPI. With an hWPI ratio of $30 \%$ the CLD decreases to $0.29 \cdot 10^{-4} \mathrm{~mol} \cdot \mathrm{g}^{-1}$. Further increase of the hWPI ratio showed no significant decrease of the CLD. At these high hWPI ratios only $0.22-$ $0.36 \%$ of all proteins are involved in forming the measureable covalent cross-links. According to Sothornvit and Krochta [29] weaker protein network interactions are formed using the shorter chains of hWPI. Generally, this does not comprise the fact that less covalent disulphide bridges are formed. The sulphide groups could be "occupied" by short chains which do not contribute to the polymeric network as shown in Figure 3. This could lead to higher $M_{c}$ values with increasing hWPI ratio.

3.2. Protein Solubility Study. The result of the protein solubility study is shown in Figure 4. It clearly shows increasing protein solubility in all buffer systems with increasing proportion of h-WPI. This is in accordance with Damodaran [30] who described an increased solubility of protein films when proteins decompose into smaller peptide units.

However, in Figure 4, it can be seen that in comparison to the other buffer systems the protein solubility increases disproportionally in the PP-TH-buffer when the content of $\mathrm{h}$-WPI in the formulation is increased. This specific buffer is mainly influencing hydrophobic interaction. Therefore this result indicates that increasing proportions of h-WPI also favors the formation of this particular noncovalent interaction.

The highest solubility of up to $70 \%$ can be achieved by cleaving hydrogen bonds and disulphide bridges. Hydrogen bonds play an important role in stabilizing secondary protein structures but also form between suitable side-chains [31]. The used urea buffer can cleave these hydrogen bonds reducing the noncovalent cross-linking of protein chains. The non-cross-linked protein chains can be better solubilized. Disulphide bonds can prevent partially the unfolding process and form links between protein molecules. Therefore the solubility can be further improved by cleaving additionally disulphide bonds.

$60-75 \%$ of the used h-WPI peptides have a molecular weight smaller than $2 \mathrm{kDa}$. The mean whey protein has a molecular weight of $41.7 \mathrm{kDa}$. The $\mathrm{h}$-WPI peptides are compared with the WPI proteins much smaller and have presumably a higher mobility in the solution. The solubility of the proteins in the $\mathrm{PP}+\mathrm{U}+\mathrm{TH}$ buffer decreases around $8 \%$ at small h-WPI ratios compared to pure WPI. In a disulphide bond disruptive buffer $(\mathrm{PP}+\mathrm{TH}+\mathrm{D})$ the solubility increases around $16 \%$. This could indicate that the shorter hWPI 
TABLE 4: Barrier properties for different ratios of h-WPI in WPI-based films and CLD with 95\% confidence intervals (stated errors of OP indicate the distance to minimum and maximum values; different letters for WVTR indicate statistically significant difference $(p<0.05))$ $[11]$.

\begin{tabular}{|c|c|c|c|c|}
\hline \multirow[b]{2}{*}{$\begin{array}{l}\text { Sample name } \\
\text { WPI : h-WPI }\end{array}$} & \multirow[b]{2}{*}{$\begin{array}{l}\text { Film } \\
\text { thickness } \\
{[\mu \mathrm{m}]}\end{array}$} & \multicolumn{2}{|c|}{ Barrier properties } & \multirow{2}{*}{$\begin{array}{c}\text { CLD } \\
\cdot 10^{-4} \\
{\left[\mathrm{~mol} \cdot \mathrm{g}^{-1}\right]}\end{array}$} \\
\hline & & $\begin{array}{l}\text { Oxygen permeability } Q_{100} \\
{\left[\mathrm{~cm}^{-3} \cdot(\mathrm{STP}) \cdot \mathrm{m}^{-2} \cdot \mathrm{d}^{-1} \cdot \mathrm{bar}^{-1}\right]}\end{array}$ & $\begin{array}{c}\text { Water vapor } \\
\text { transmission rate } \\
{\left[\mathrm{g} \cdot \mathrm{m}^{-2} \cdot \mathrm{d}^{-1}\right]}\end{array}$ & \\
\hline $\begin{array}{l}\text { BioZate10_0 } \\
10: 0\end{array}$ & $183 \pm 9$ & $101( \pm 6)$ & $177 \pm 6^{(a)}$ & $1.15 \pm 0.28$ \\
\hline $\begin{array}{l}\text { BioZate9_1 } \\
9: 1\end{array}$ & $191 \pm 18$ & $145( \pm 9)$ & $257 \pm 20^{(\mathrm{bc})}$ & $1.2 \pm 0.5$ \\
\hline $\begin{array}{l}\text { BioZate8_2 } \\
8: 2\end{array}$ & $186 \pm 7$ & $99( \pm 8)$ & $194 \pm 7^{(\mathrm{ab})}$ & $0.55 \pm 0.17$ \\
\hline $\begin{array}{l}\text { BioZate7_3 } \\
7: 3\end{array}$ & $196 \pm 12$ & $123( \pm 3)$ & $253 \pm 6^{(\mathrm{bc})}$ & $0.29 \pm 0.12$ \\
\hline $\begin{array}{l}\text { BioZate6_4 } \\
6: 4\end{array}$ & $211 \pm 16$ & $82( \pm 5)$ & $222 \pm 16^{(\mathrm{b})}$ & $0.27 \pm 0.10$ \\
\hline $\begin{array}{l}\text { BioZate5_5 } \\
5: 5\end{array}$ & $198 \pm 8$ & $208( \pm 20)$ & $264 \pm 10^{(c)}$ & $0.18 \pm 0.13$ \\
\hline
\end{tabular}

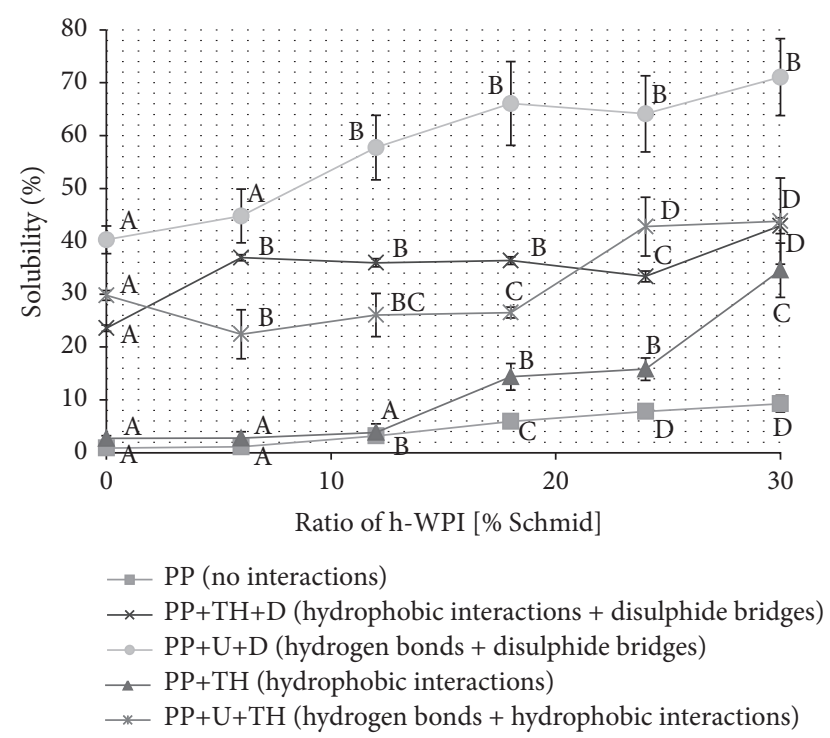

FIgURE 4: Protein solubility in WPI-based coatings dependent on the h-WPI ratio (different letters indicate statistically significant differences $(p<0.05))$.

peptides could orientate and arrange better in the solution to form disulphide bonds with other proteins to form larger and more insoluble protein aggregates. A similar observation was also seen in the CLD measurements. With a low h-WPI concentration of $10 \%$ the CLD was around $1.24 \cdot 10^{-4} \mathrm{~mol} \cdot \mathrm{g}^{-1}$ compared to $1.15 \cdot 10^{-4} \mathrm{~mol} \cdot \mathrm{g}^{-1}$ with no h-WPI. Therefore it can be assumed that an hWPI ratio of less than 10\% boosts the disulphide bond cross-linking resulting in higher CLDs.

3.3. CLD Correlation with Barrier Properties. In order to evaluate whether there is a correlation between the CLD and resulting technofunctional properties, such as barrier properties, it was necessary to compare the observed CLD values with permeability properties already published by Schmid et al. [11]. This is possible and reasonable, as they have used the same formulations for their study.

Table 4 shows the oxygen permeability (OP) as well as the water vapor transmission rate (WVTR) of WPI-based films with different h-WPI contents. OP values are standardized to a film thickness of $100 \mu \mathrm{m}$. The WVTR values are valid for the measured film thickness. No significant correlation between the h-WPI ratio and the OP values was observed. Thus, the barrier properties are not significantly affected by changing CLD values. The samples Biozate10_0 to BioZate6_4 show OP values of around $80-150 \mathrm{~cm}^{3} \cdot(\mathrm{STP}) \cdot \mathrm{m}^{-2} \cdot \mathrm{d}^{-1} \cdot \mathrm{bar}^{-1}$. A tendency towards higher $\mathrm{OP}$ is only recognizable for BioZate5_5. The results of Sothornvit and Krochta [29] who also determined only a minimal effect of h-WPI on OP values are thus confirmed.

The WVTR values show also no significant correlation with changing h-WPI ratio. This result is consistent with Sothornvit and Krochta [32] who analyzed the effect of h-WPI concentration on WVTR values [11].

Generally, the whey protein structure and the CLD have an influence on the WVTR. Nevertheless, this study showed that the maximum CLD resulting from disulphide bonds seems to be too low for a significant improvement of barrier properties. Presumably higher CLD can be achieved with Transglutaminase resulting in a significant improvement of barrier properties up to a factor of five [6]. In this study no correlation between CLD and barrier properties was observed. Therefore it can be assumed that the barrier properties of WPI-based films are mainly affected by noncovalent interactions when using nonenzymatic treatments.

\section{Conclusions}

Quantitative calculation of the degree of cross-linking as well as determination of the cross-link density in different film formulations was performed with the help of swelling tests. 
The missing solubility parameter $\chi$ for the CLD calculation was determined from the water vapor sorption isotherm. The mean interaction parameter was determined to be $\bar{\chi}=$ $0.460 \pm 0.017$.

The DoC for WPI-based films with increasing h-WPI contents decreases significantly from $1.42 \%$ to $0.22 \%$. WPIbased films without h-WPI showed a CLD of 1.15 . $10^{-4} \mathrm{~mol} \cdot \mathrm{g}^{-1}$ which is slightly lower than that of natural rubber. Solubility studies and swelling tests indicate that the CLD is increased with h-WPI ratios of $6 \%$ to $10 \%$. It is assumed that the shorter h-WPI peptides can form easier disulphide bonds due to their higher mobility in the solution. Thus the WPI proteins could be easier connected via hWPI peptides. At higher h-WPI contents the CLD decreases similar to the DoC. The barrier properties against water vapor and oxygen show no significant change with increasing $h-$ WPI content as observed by Schmid et al. [11]. This could indicate that the WPI barrier properties are also mainly influenced due to noncovalent interactions at the measured CLDs.

In summary, quantitative assessment of the number of disulfide bonds by swelling experiments (determination of the respective CLD) in WPI-based films was performed. The solubility studies allowed determination of the different molecular interactions in the films. Generally, the quantitative results of the swelling studies confirm the results of the protein solubility studies.

\section{Competing Interests}

The authors declare that they have no conflict of interests.

\section{Acknowledgments}

This work was supported by the German Research Foundation (DFG) and the Technical University of Munich (TUM) in the framework of the Open Access Publishing Program. The authors thank the DFG and the TUM for their support.

\section{References}

[1] G. L. Robertson, Food Packaging: Principles and Practice, CRC Press, 2012.

[2] M.-B. Coltelli, F. Wild, E. Bugnicourt et al., "State of the art in the development and properties of protein-based films and coatings and their applicability to cellulose based products: an extensive review," Coatings, vol. 6, no. 1, p. 1, 2016.

[3] M. Schmid, K. Dallmann, E. Bugnicourt et al., "Properties of whey-protein-coated films and laminates as novel recyclable food packaging materials with excellent barrier properties," International Journal of Polymer Science, vol. 2012, Article ID 562381, 7 pages, 2012.

[4] M. Schmid, B. Krimmel, U. Grupa, and K. Noller, "Effects of thermally induced denaturation on technological-functional properties of whey protein isolate-based films," Journal of Dairy Science, vol. 97, no. 9, pp. 5315-5327, 2014.

[5] M. Wihodo and C. I. Moraru, "Physical and chemical methods used to enhance the structure and mechanical properties of protein films: a review," Journal of Food Engineering, vol. 114, no. 3, pp. 292-302, 2013.

[6] M. Schmid, S. Sängerlaub, L. Wege, and A. Stäbler, "Properties of transglutaminase crosslinked whey protein isolate coatings and cast films," Packaging Technology and Science, vol. 27, no. 10, pp. 799-817, 2014.

[7] J. Zink, T. Wyrobnik, T. Prinz, and M. Schmid, "Physical, chemical and biochemical modifications of protein-based films and coatings: an extensive review," International Journal of Molecular Sciences, vol. 17, no. 9, p. 1376, 2016.

[8] F. Hammann and M. Schmid, "Determination and quantification of molecular interactions in protein films: a review," Materials, vol. 7, no. 12, pp. 7975-7996, 2014.

[9] J. P. C. M. Peters, H. Luyten, A. C. Alting, R. M. Boom, and A. J. van der Goot, "Effect of crosslink density on the water-binding capacity of whey protein microparticles," Food Hydrocolloids, vol. 44, pp. 277-284, 2015.

[10] M. Karimi, W. Albrecht, M. Heuchel et al., "Determination of water/polymer interaction parameter for membrane-forming systems by sorption measurement and a fitting technique," Journal of Membrane Science, vol. 265, no. 1-2, pp. 1-12, 2005.

[11] M. Schmid, L.-V. Hinz, F. Wild, and K. Noller, "Effects of hydrolysed whey proteins on the techno-functional characteristics of whey protein-based films," Materials, vol. 6, no. 3, pp. 927-940, 2013.

[12] T. H. Mchugh, J. F. Aujard, and J. Krochta, "Plasticized whey protein edible films: water vapor permeability properties," Journal of Food Science, vol. 59, no. 2, pp. 416-419, 1994.

[13] K. S. Liu and F.-H. Hsieh, "Protein-protein interactions in high moisture-extruded meat analogs and heat-induced soy protein gels," Journal of the American Oil Chemists' Society, vol. 84, no. 8, pp. 741-748, 2007.

[14] M. Schmid, K. Reichert, F. Hammann, and A. Stäbler, "Storage time-dependent alteration of molecular interaction-property relationships of whey protein isolate-based films and coatings," Journal of Materials Science, vol. 50, no. 12, pp. 4396-4404, 2015.

[15] M. M. Bradford, "A rapid and sensitive method for the quantitation of microgram quantities of protein utilizing the principle of protein-dye binding," Analytical Biochemistry, vol. 72, no. 1-2, pp. 248-254, 1976.

[16] S. J. Compton and C. G. Jones, "Mechanism of dye response and interference in the Bradford protein assay," Analytical Biochemistry, vol. 151, no. 2, pp. 369-374, 1985.

[17] DIN, "Kunststoffe-Prüfverfahren zur Bestimmung des Verhaltens gegen flüssige Chemikalien," DIN EN ISO 175:2010-10, 2010.

[18] K. Ahmed, S. S. Nizami, N. Z. Raza, and K. Mahmood, "Mechanical, swelling, and thermal aging properties of marble sludgenatural rubber composites," International Journal of Industrial Chemistry, vol. 3, no. 1, pp. 1-12, 2012.

[19] A. Marzocca, "Evaluation of the polymersolvent interaction parameter $\chi$ for the system cured styrene butadiene rubber and toluene," European Polymer Journal, vol. 43, no. 6, pp. 26822689, 2007.

[20] Z. Y. Ding, J. J. Aklonis, and R. Salovey, "Model filled polymers. VI. Determination of the crosslink density of polmeric beads by swelling," Journal of Polymer Science, Part B: Polymer Physics, vol. 29, no. 8, pp. 1035-1038, 1991.

[21] B. Isik and M. Kis, "Preparation and determination of swelling behavior of poly(acrylamide-co-acrylic acid) hydrogels in water," Journal of Applied Polymer Science, vol. 94, no. 4, pp. 1526-1531, 2004. 
[22] E. Favre, Q. T. Nguyen, P. Schaetzel, R. Clément, and J. Néel, "Sorption of organic solvents into dense silicone membranes. Part 1.- validity and limitations of Flory-Huggins and related theories," Journal of the Chemical Society, Faraday Transactions, vol. 89, no. 24, pp. 4339-4346, 1993.

[23] J. L. Valentín, J. Carretero-González, I. Mora-Barrantes, W. Chassé, and K. Saalwächter, "Uncertainties in the determination of cross-link density by equilibrium swelling experiments in natural rubber," Macromolecules, vol. 41, no. 13, pp. 4717-4729, 2008.

[24] P. J. Flory, "Thermodynamics of high polymer solutions," The Journal of Chemical Physics, vol. 9, no. 8, pp. 660-661, 1941.

[25] M. L. Huggins, "Solutions of long chain compounds," The Journal of Chemical Physics, vol. 9, no. 5, p. 440, 1941.

[26] L. Figura and A. A. Teixeira, Food Physics: Physical PropertiesMeasurement and Applications, Springer, Berlin, Germany, 2007.

[27] M. S. Suwandi and S. A. Stern, "Transport of heavy organic vapors through silicone rubber," Journal of Polymer Science: Polymer Physics Edition, vol. 11, no. 4, pp. 663-681, 1973.

[28] M. Schmid, "Properties of cast films made from different ratios of whey protein isolate, hydrolysed whey protein isolate and glycerol," Materials, vol. 6, no. 8, pp. 3254-3269, 2013.

[29] R. Sothornvit and J. M. Krochta, "Oxygen permeability and mechanical properties of films from hydrolyzed whey protein," Journal of Agricultural and Food Chemistry, vol. 48, no. 9, pp. 3913-3916, 2000.

[30] S. Damodaran, Food Proteins and Their Applications, Taylor \& Francis, Oxfordshire, UK, 1997.

[31] N. Sewald and H. D. Jakubke, Peptides: Chemistry and Biology, John Wiley \& Sons, Berlin, Germany, 2015.

[32] R. Sothornvit and J. M. Krochta, "Water vapor permeability and solubility of films from hydrolyzed whey protein," Journal of Food Science, vol. 65, no. 4, pp. 700-703, 2000. 

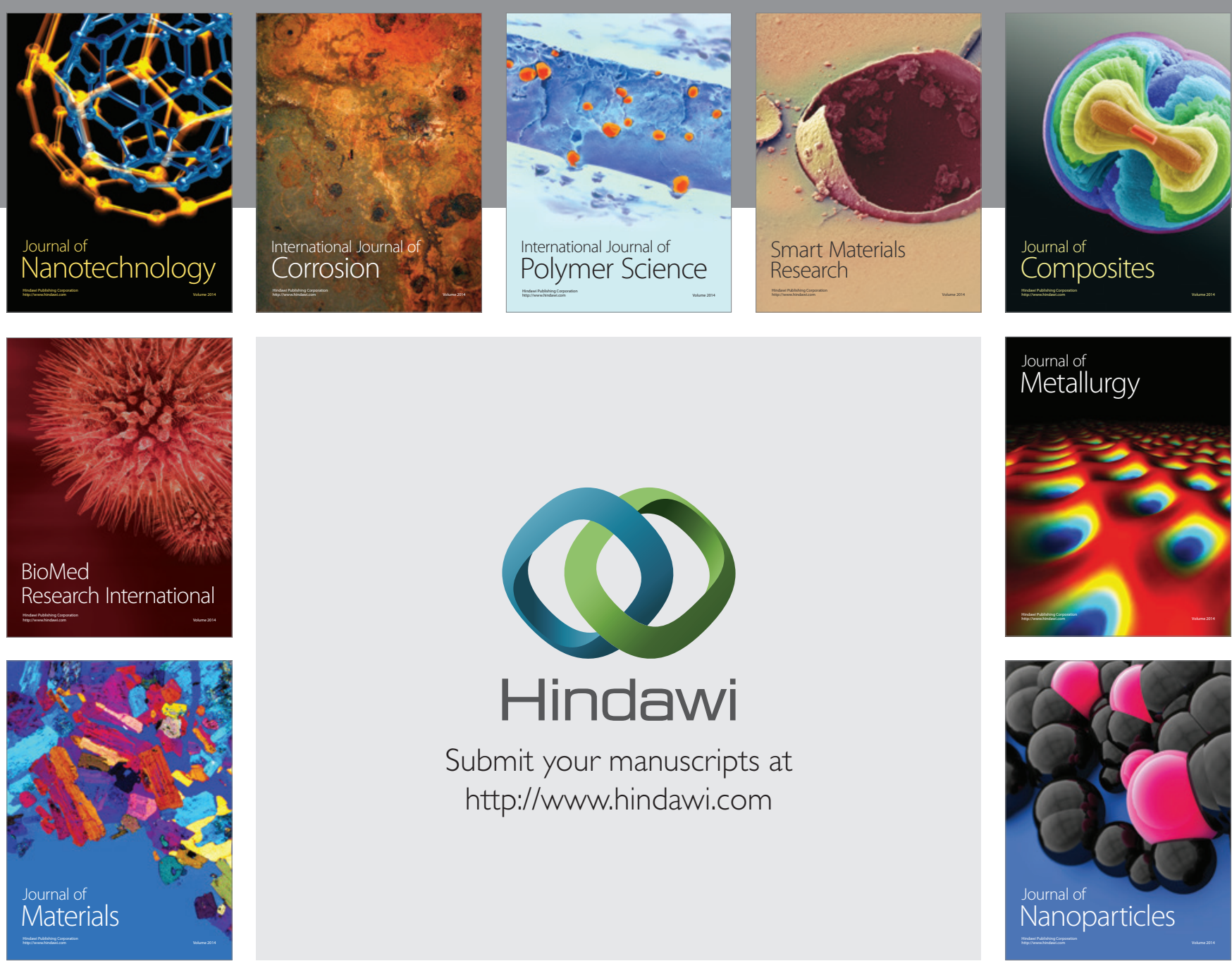

\section{Hindawi}

Submit your manuscripts at

http://www.hindawi.com

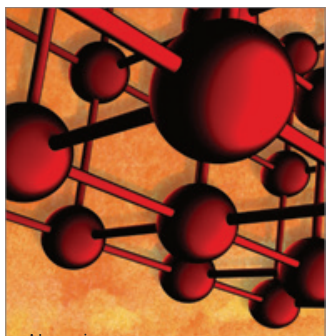

Materials Science and Engineering
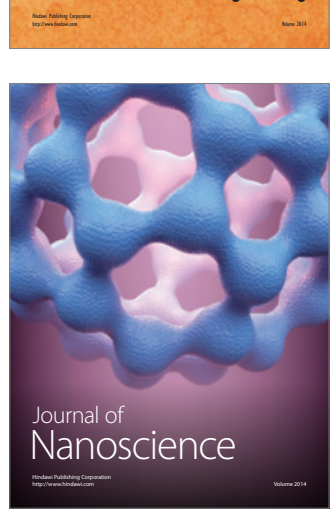
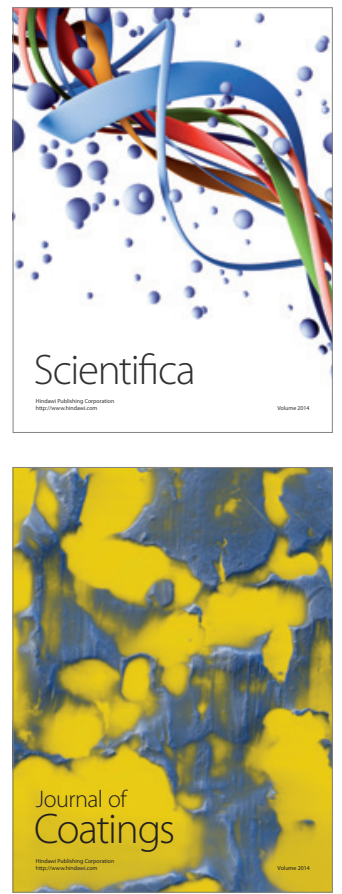
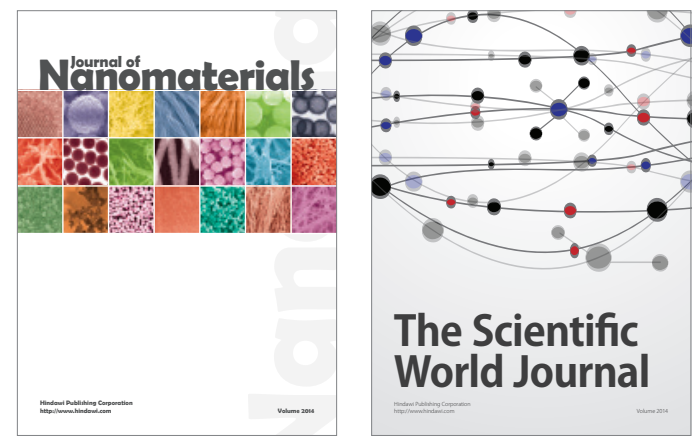

The Scientific World Journal
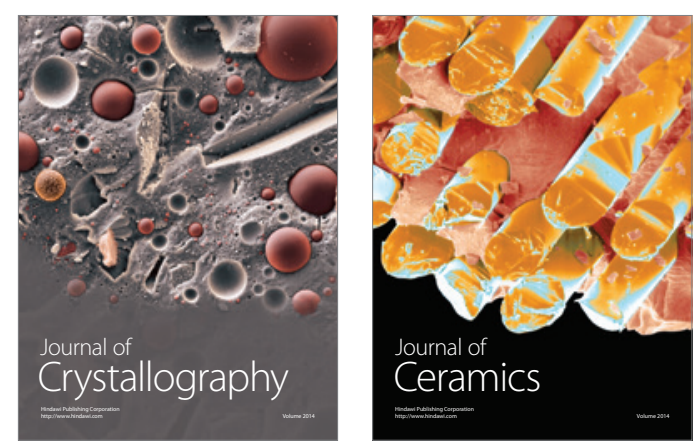
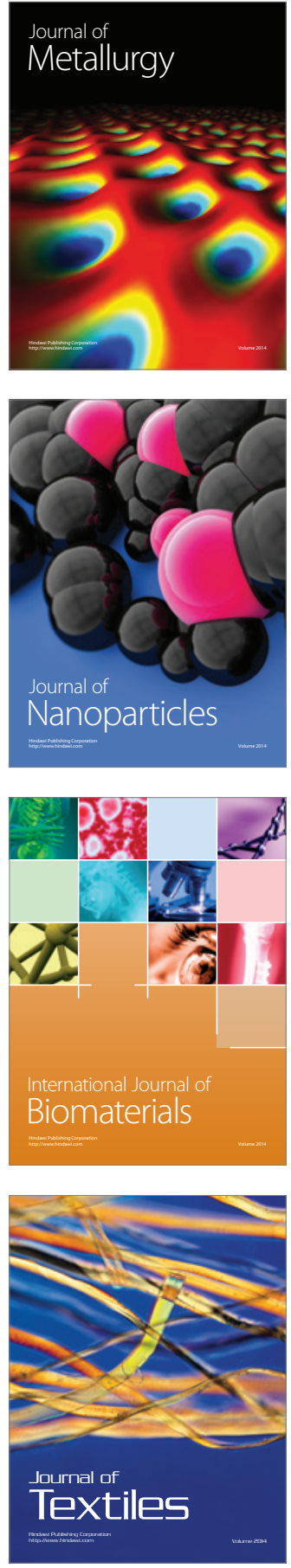